\title{
openheart Atrial fibrillation and clinical outcomes 1 to 3 years after myocardial infarction
}

Anthony P Carnicelli (D) , ${ }^{1}$ Ruth Owen, ${ }^{2}$ Stuart J Pocock (D) , ${ }^{3}$ David B Brieger (D) , ${ }^{4}$ Satoshi Yasuda, ${ }^{5}$ Jose Carlos Nicolau, ${ }^{6}$ Shaun G Goodman, ${ }^{7}$ Mauricio G Cohen, ${ }^{8}$ Tabassome Simon, ${ }^{9,10}$ Dirk Westermann (D) , ${ }^{11,12}$ Katarina Hedman, ${ }^{13}$ Karolina Andersson Sundell, ${ }^{13}$ Christopher B Granger (1) ${ }^{14}$

- Additional supplemental material is published online only. To view, please visit the journal online (http://dx.doi.org/10. 1136/openhrt-2021-001726).

To cite: Carnicelli AP, Owen R, Pocock SJ, et al. Atrial fibrillation and clinical outcomes 1 to 3 years after myocardial infarction. Open Heart 2021;8:e001726. doi:10.1136/ openhrt-2021-001726

Received 19 May 2021 Accepted 8 November 2021

Check for updates

(c) Author(s) (or their employer(s)) 2021. Re-use permitted under CC BY-NC. No commercial re-use. See rights and permissions. Published by BMJ.

For numbered affiliations see end of article.

Correspondence to Dr Christopher B Granger; grang001@mc.duke.edu

\section{ABSTRACT}

Objective Atrial fibrillation (AF) and myocardial infarction (MI) are commonly comorbid and associated with adverse outcomes. Little is known about the impact of AF on quality of life and outcomes post-MI. We compared characteristics, quality of life and clinical outcomes in stable patients post-Ml with/without AF.

Methods/results The prospective, international, observational TIGRIS (long Term rlsk, clinical manaGement and healthcare Resource utilization of stable coronary artery dISease) registry included 8406 patients aged $\geq 50$ years with $\geq 1$ atherothrombotic risk factor who were $1-3$ years post-MI. Patient characteristics were summarised by history of AF. Quality of life was assessed at baseline using EQ-5D. Clinical outcomes over 2 years of follow-up were compared. History of AF was present in 702/8277 $(8.5 \%)$ registry patients and incident AF was diagnosed in 244/7575 (3.2\%) over 2 years. Those with AF were older and had more comorbidities than those without AF. After multivariable adjustment, patients with AF had lower self-reported quality-of-life scores (EQ-5D UK-weighted index, visual analogue scale, usual activities and pain/ discomfort) than those without AF. CHA $\mathrm{DS}_{2}$-VASc score $\geq 2$ was present in 686/702 (97.7\%) patients with AF, although only 348/702 (49.6\%) were on oral anticoagulants at enrolment. Patients with AF had higher rates of all-cause hospitalisation (adjusted rate ratio 1.25 [1.06-1.46], $\mathrm{p}=0.008$ ) over 2 years than those without $A F$, but similar rates of mortality.

Conclusions In stable patients post-Ml, those with AF were commonly undertreated with oral anticoagulants, had poorer quality of life and had increased risk of clinical outcomes than those without AF.

Trial registration number ClinicalTrials: NCT01866904.

\section{INTRODUCTION}

Atrial fibrillation (AF) is the most common sustained arrhythmia, occurring in 5\% to $10 \%$ of patients with myocardial infarction (MI). ${ }^{1-3}$ Approximately one in five strokes are caused by AF, although most AF-related strokes can be prevented with oral anticoagulants (OAC). ${ }^{45}$ The major hazard associated with OAC is bleeding, the risk of which is substantially increased when OAC is combined with antiplatelet therapy after MI. ${ }^{6}$

\section{Key messages}

What is already known about this subject?

- Atrial fibrillation and myocardial infarction share multiple common risk factors and are often comorbid.

What does this study add?

- In patients with a history of myocardial infarction enrolled in the TIGRIS registry, atrial fibrillation was associated with poorer quality-of-life measures.

- Among patients with a history of atrial fibrillation, oral anticoagulant use was low.

How might this impact on clinical practice?

- Clinicians should consider the potential impact that atrial fibrillation may have on patient-centred outcomes such as quality of life.

- Strategies are needed to increase the use of ora anticoagulants and thus improve clinical outcomes.

$\mathrm{AF}$ is a well-established risk factor associated with considerable morbidity and mortality after MI. ${ }^{37}$ Patients with a history of prior MI and concomitant AF comprise an important group at heightened risk for cardiovascular events, including hospitalisations for heart failure, bleeding and mortality. Characteristics and outcomes of stable patients with prevalent or incident AF after recovery from MI are not well described. We therefore sought to describe characteristics, quality-oflife (QoL) measures, treatment patterns and clinical outcomes of patients with prevalent or incident AF following MI using data from the TIGRIS (long Term rIsk, clinical mana Gement and healthcare Resource utilization of stable coronary artery dISease) registry, which includes a unique international population with MI 1-3 years before enrolment.

\section{METHODS}

\section{Registry design}

The TIGRIS registry was a prospective, observational registry that enrolled 8406 patients 
(8277 with any follow-up data up to 2 years) from 24 countries in Asia-Pacific/Australia, Europe, North America and South America during June 2013 to November 2014. Its main objective was to better understand the long-term outcomes and associated healthcare utilisation in stable patients with MI that occurred 1-3 years before enrolment. A list of Principal Investigators can be found in online supplemental table S1. TIGRIS registry enrolment criteria and patient characteristics have been published. ${ }^{89}$ Patients were aged $\geq 50$ years, had a documented history of MI and had $\geq 1$ additional cardiovascular risk factor. Notable exclusion criteria were treatment with ticagrelor beyond 12 months post-MI or off-label use of ticagrelor.

The TIGRIS registry was performed in accordance with ethical principles that are consistent with the Declaration of Helsinki, the International Council for Harmonisation Good Clinical Practice Guidelines and applicable legislation on non-interventional studies. All participants provided written informed consent. The registry protocol and informed consent were reviewed by the corresponding health authorities and ethics boards of all participating registry sites.

A standardised electronic case report form was used for data collection. Data were collected during the initial visit and every 6 months thereafter for 24 months, by telephone or in person. Interim hospitalisations and other health resource utilisation items were based on patient recall.

Registry participant QoL was assessed at each visit using the EuroQol Research Foundation survey instrument (EuroQol-5 dimension, EQ-5D), which measures selfreported health status in five domains (mobility, self-care, usual activities, pain/discomfort and anxiety/depression) with three levels of severity (none, moderate and severe) ${ }^{10}$ The EuroQol EQ-5D QoL assessment has been studied and validated across a variety of cardiovascular diseases, including in patients with prior $\mathrm{MI}^{11}{ }^{12}$ and $\mathrm{AF}^{13}{ }^{14} \mathrm{EQ}-5 \mathrm{D}$ survey data were used to generate UK-weighted index scores, which are widely accepted as a valid summary of overall health status. ${ }^{15}$ A score of 1 indicates "no problems' on all five domains and a score below 1 indicates increasingly poor self-rated health status, down to a minimum score of 0 .

\section{Atrial fibrillation analysis}

For the present analysis, we first stratified patients by presence or absence of history of $\mathrm{AF}$ at the time of enrolment. Patients without a history of AF were further stratified by development of incident AF during up to 2 years of follow-up. Incident AF was diagnosed by local participating site standard of care and was collected in the TIGRIS registry as a binary (yes/no) variable. Baseline characteristics examined included vital signs, smoking status, living situation, comorbidities, medical history, details of the index MI, EQ-5D scores, EQ-5D UK-weighted index scores and medications at enrolment. Changes in OAC and antiplatelet therapies as well as hospitalisation for any cause, cardiovascular causes and bleeding throughout the follow-up were analysed. Clinical outcomes examined included all-cause mortality, MI, stroke, unstable angina with urgent revascularisation, cardiovascular mortality, bleeding requiring hospitalisation, a primary composite outcome (all-cause mortality, MI, stroke, unstable angina requiring urgent revascularisation) and a secondary composite outcome (cardiovascular mortality, MI, stroke).

\section{Statistical analysis}

Comparisons of baseline characteristics and baseline QoL scores by history of AF and by incident AF after enrolment were summarised by mean and SD for quantitative variables and by frequency/percentage for categorical variables. Notably, $\mathrm{p}$ values were based on a two-sample t-test, $\chi^{2}$ test and test for trends for quantitative, binary and ordinal variables, respectively; $p$ values were also used for expressing the association between enrolment variables and incident AF during follow-up. The 2-year cumulative incidence (risk \%) of each clinical outcome was calculated by history of AF using Kaplan-Meier estimates to account for patients lost to follow-up, and univariable comparisons were made using log-rank tests.

Unadjusted incidence rate ratios for each clinical outcome were calculated for patients with a history of AF using patients without a history of $\mathrm{AF}$ as the reference group. A multivariable Poisson regression model was used to calculate the adjusted incidence rate ratios for individual and composite outcomes. Covariates simultaneously adjusted for were those in the TIGRIS risk index model. ${ }^{16} \mathrm{~A}$ corresponding multivariable regression model was used for all-cause hospitalisation (for patients with complete hospitalisation data), simultaneously adjusting for predictors of all-cause hospitalisation (table 1 footnote).

Multivariable logistic regression models were used to identify independent factors associated with OAC use at enrolment and incident $\mathrm{AF}$ after enrolment using a forward stepwise procedure with $\mathrm{p}<0.05$. To estimate the adjusted association between history of AF and selfreported QoL at enrolment, we used multivariable ordinal logistic models for EQ-5D UK-weighted index score (categorised as $<0.60,0.60-0.74,0.75-0.99$ and 1$)$, EQ-5D VAS score (categorised as $<60,60-69,70-79,80-89$ and $\geq 90$ ) and each individual item (mobility, self-care, usual activities, pain/discomfort and anxiety/depression), adjusting for other baseline factors associated with QoL. ORs with 95\% CIs for independent predictors were calculated from multivariable logistic models and common ORs of being in a 'lowest' versus 'highest' category, according to the presence versus absence of $\mathrm{AF}$ at history, were estimated from multivariable ordinal logistic models.

Number of hospitalisations for any cause, cardiovascular cause or bleeding over the 2-year follow-up period were calculated for patients with a history of AF before enrolment and compared with those without a history of AF using a two-sample t-test, which is valid despite the skewed nature of the data because the Central Limit 
Table 1 Association of atrial fibrillation history with unadjusted and adjusted rate ratios for clinical outcomes (reference group is patients with no history of atrial fibrillation)

\begin{tabular}{|c|c|c|c|c|}
\hline Outcome & Unadjusted RR (95\% Cl) & $P$ value & Adjusted RR $(95 \% \mathrm{Cl})^{\star} \dagger$ & $P$ value \\
\hline All-cause mortality & 2.16 (1.57 to 2.98$)$ & $<0.001$ & 0.98 (0.70 to 1.38$)$ & 0.93 \\
\hline $\begin{array}{l}\text { Bleeding event requiring } \\
\text { hospitalisation }\end{array}$ & 2.61 (1.58 to 4.30$)$ & $<0.001$ & 1.64 (0.96 to 2.82) & 0.07 \\
\hline All-cause hospitalisation & $1.76(1.50$ to 2.06$)$ & $<0.001$ & 1.25 (1.06 to 1.46$)$ & 0.008 \\
\hline Primary composite & 1.61 (1.26 to 2.06$)$ & $<0.001$ & 0.92 (0.71 to 1.20$)$ & 0.53 \\
\hline
\end{tabular}

Primary composite=all-cause mortality, myocardial infarction, stroke, unstable angina with urgent revascularisation. Secondary composite=cardiovascular mortality, myocardial infarction, stroke.

${ }^{*}$ Composite, all-cause mortality and bleeding requiring hospitalisation outcomes adjusted for variables in the TIGRIS risk index model: age $\geq 65$ years, diabetes, second prior MI, chronic kidney disease, heart failure, peripheral artery disease, major bleed, medical management of index $\mathrm{Ml}$, diuretics, region and country as random effects.

†All-cause hospitalisation outcome (from 7170 patients with complete hospitalisation data) adjusted for predictors of all-cause hospitalisation: cardiovascular event requiring hospital stay 6 months before enrolment, diuretic, chronic kidney disease, age $\geq 65$ years, second prior MI, diabetes, history of cancer, permanent pacemaker, history of COPD, systolic blood pressure, implantable cardioverter defibrillator, history of major bleed, history of angina, cardiologist visit 6 months before enrolment, region, statin or other lipid-lowering drug and history of anaemia.

COPD, chronic obstructive pulmonary disease; CV, cardiovascular; MI, myocardial infarction; RR, rate ratio; TIGRIS, long Term rlsk, clinical manaGement and healthcare Resource utilization of stable coronary artery dISease registry.

Theorem can be applied owing to the large sample size in the trial. All analyses were performed using STATA V.15.1.

\section{RESULTS}

\section{Baseline characteristics}

A total of $702 / 8277(8.5 \%)$ patients from the TIGRIS registry had a history of AF at enrolment (online supplemental table S2). Patients with a history of AF were older and had a higher burden of comorbidities including prior MI, chronic kidney disease, heart failure, valvular heart disease and malignancy. Of the 702 patients with a history of AF, $686(97.7 \%)$ had a $\mathrm{CHA}_{2} \mathrm{DS}_{2}$-VASc score $\geq 2$ and 143 $\left(20.4 \%\right.$ ) had a $\mathrm{CHA}_{2} \mathrm{DS}_{2}$-VASc score $\geq 6$ (online supplemental table S3).

Of 7575 patients without a history of AF, 244 (3.2\%) were diagnosed with incident AF over 2 years of follow-up (incidence rate 16.5 [95\% CI 14.6 to 18.8] per 1000 person-years). Baseline characteristics of patients without a history of $\mathrm{AF}$, stratified by presence of incident $\mathrm{AF}$ after enrolment, are included in the online supplement (table 2). Patients with incident AF had higher body mass indices; were more likely to have a history of heart failure, angina and chronic obstructive pulmonary disease; and were more likely to have a clinical encounter within the preceding 6 months (such as a cardiovascular event requiring hospitalisation, cardiac surgery, emergency department (ED) visit or general practitioner visit).

\section{Oral anticoagulant and antiplatelet therapy patterns}

At enrolment, 348/702 (49.6\%) patients with a history of $\mathrm{AF}$ were on OAC and 106/702 (15.1\%) were on dual antiplatelet therapy (DAPT; with or without OAC) (online supplemental table S2). Details of patients with a history of AF stratified by $\mathrm{CHA}_{2} \mathrm{DS}_{2}$-VASc score and OAC use at enrolment can be found in online supplemental table S3. Among patients with a history of AF on OAC $(n=348)$, $58.3 \%$ (203) were on warfarin and $41.7 \%$ (145) were on an alternative OAC (online supplemental table S4). A forest plot showing baseline characteristics independently associated with OAC use at enrolment in patients with a history of AF is shown in figure 1. These included history of visit to cardiologist within the preceding 6 months, history of implantable cardioverter defibrillator placement, history of stroke or transient ischaemic attack, and geographic region.

After 2 years of follow-up, 37 patients who were on OAC at enrolment had discontinued OAC and 49 patients who were not on OAC at enrolment had initiated OAC. Similarly, after 2 years of follow-up, 34 patients who were on DAPT at enrolment had discontinued DAPT and 25 patients who were not on DAPT at enrolment had initiated DAPT.

Of the 702 patients with a history of AF, 24 (3.4\%) were on 'triple therapy' (OAC and concomitant DAPT) at enrolment, whereas $153 / 702(21.8 \%)$ were on 'dual therapy' (OAC and single antiplatelet therapy) and $171 / 702(24.4 \%)$ were on OAC alone without antiplatelet therapy. The majority of patients without a history of AF $(n=7575)$ were either on single antiplatelet therapy without OAC $(\mathrm{n}=5208 ; 68.8 \%)$ or DAPT without OAC $(\mathrm{n}=1969 ; 26.0 \%)$ at enrolment.

\section{Quality of life}

At enrolment, patients with a history of AF reported significantly lower self-reported health scores than patients without $\mathrm{AF}$ (table 3). Of the five domains included in the EQ-5D assessment, patients with AF reported significantly worse mobility, self-care, usual activities and pain compared with patients without a history of AF. Patients 
Table 2 Baseline characteristics of patients without a history of atrial fibrillation at enrolment, stratified by presence or absence of incident atrial fibrillation after enrolment

\begin{tabular}{|c|c|c|c|}
\hline Variable & $\begin{array}{l}\text { No incident } \\
\text { AF } \\
(\mathrm{N}=7331)\end{array}$ & $\begin{array}{l}\text { Incident AF } \\
(\mathrm{N}=244)\end{array}$ & $P$ value \\
\hline & \multicolumn{3}{|c|}{ Demographics and clinical variables } \\
\hline Female & $1743(23.8)$ & $69(28.3)$ & 0.10 \\
\hline Age (years) & $66.8(8.6)$ & $66.3(8.8)$ & 0.43 \\
\hline $\mathrm{BMI}\left(\mathrm{kg} / \mathrm{m}^{2}\right)$ & $27.5(4.7)$ & $28.5(4.8)$ & 0.001 \\
\hline $\mathrm{SBP}(\mathrm{mm} \mathrm{Hg})$ & $131.5(17.7)$ & $133.5(18.1)$ & 0.09 \\
\hline Heart rate (bpm) & $68.2(10.7)$ & $67.7(11.5)$ & 0.48 \\
\hline \multicolumn{4}{|l|}{ Smoking status } \\
\hline Never & 2731 (37.3) & $90(36.9)$ & 0.56 \\
\hline Former & $3589(49.0)$ & $115(47.1)$ & \\
\hline Current & $1010(13.8)$ & $39(16.0)$ & \\
\hline Living alone & $1034(14.3)$ & $28(11.5)$ & 0.23 \\
\hline Region & & & $<0.001$ \\
\hline Europe & 3532 (48.2) & $188(77.1)$ & \\
\hline Asia and Australia & $1935(26.4)$ & $7(2.9)$ & \\
\hline Latin America & $1027(14.0)$ & $32(13.1)$ & \\
\hline North America & $837(11.4)$ & $17(7.0)$ & \\
\hline \multicolumn{4}{|c|}{ Comorbidities and medical history } \\
\hline Diabetes mellitus & & & 0.80 \\
\hline No diabetes & $4875(67.0)$ & $164(67.8)$ & \\
\hline Non-insulin-treated & $1724(23.7)$ & $56(23.1)$ & \\
\hline Insulin-treated & $681(9.4)$ & $22(9.1)$ & \\
\hline Second prior Ml & $739(10.1)$ & 33 (13.5) & 0.08 \\
\hline Chronic kidney disease & $535(7.3)$ & $28(11.5)$ & 0.01 \\
\hline Major bleeding & $182(2.5)$ & $7(2.9)$ & 0.70 \\
\hline $\begin{array}{l}\text { Peripheral arterial } \\
\text { disease }\end{array}$ & $474(6.5)$ & $19(7.8)$ & 0.08 \\
\hline Congestive heart failure & $748(10.2)$ & $39(16.0)$ & 0.004 \\
\hline Angina & $709(9.7)$ & $54(22.1)$ & $<0.0001$ \\
\hline $\begin{array}{l}\text { Valve replacement/ } \\
\text { repair }\end{array}$ & $58(0.8)$ & $2(0.8)$ & 0.96 \\
\hline $\begin{array}{l}\text { Stroke or transient } \\
\text { ischaemic attack }\end{array}$ & $387(5.3)$ & $12(4.9)$ & 0.80 \\
\hline Cancer & $505(6.9)$ & $17(7.0)$ & 0.96 \\
\hline COPD & $494(6.7)$ & 27 (11.1) & 0.009 \\
\hline $\begin{array}{l}\text { CV event requiring } \\
\text { hospital stay in the past } \\
6 \text { months }\end{array}$ & $313(4.3)$ & $20(8.2)$ & 0.003 \\
\hline $\begin{array}{l}\text { Bleeding event requiring } \\
\text { hospital stay in the past } \\
6 \text { months }\end{array}$ & $42(0.6)$ & $3(1.2)$ & 0.19 \\
\hline $\begin{array}{l}\text { Cardiac surgery in the } \\
\text { past } 6 \text { months }\end{array}$ & $28(0.4)$ & $4(1.6)$ & 0.003 \\
\hline
\end{tabular}

Continued
Table 2 Continued

\begin{tabular}{|c|c|c|c|}
\hline Variable & $\begin{array}{l}\text { No incident } \\
\text { AF } \\
(\mathrm{N}=7331)\end{array}$ & $\begin{array}{l}\text { Incident AF } \\
(\mathrm{N}=244)\end{array}$ & $P$ value \\
\hline $\begin{array}{l}\text { Visit to the cardiologist } \\
\text { in the past } 6 \text { months }\end{array}$ & 2324 (31.7) & $83(34.0)$ & 0.44 \\
\hline $\begin{array}{l}\text { ED visit in the past } 6 \\
\text { months for bleeding or } \\
\text { CV disease }\end{array}$ & $384(5.2)$ & $31(12.7)$ & $<0.0001$ \\
\hline $\begin{array}{l}\text { GP visit in the past } 6 \\
\text { months for bleeding or } \\
\text { CV disease }\end{array}$ & $1467(20.0)$ & 59 (24.2) & 0.11 \\
\hline \multicolumn{4}{|c|}{ Details of index event } \\
\hline Type of index Ml & & & 0.47 \\
\hline STEMI & $3724(50.8)$ & $121(49.6)$ & \\
\hline NSTEMI & 3125 (42.6) & $111(45.5)$ & \\
\hline Unknown & $482(6.6)$ & $12(4.9)$ & \\
\hline $\begin{array}{l}\text { Management of index } \\
\text { MI }\end{array}$ & & & 0.06 \\
\hline $\mathrm{PCl}$ & 5977 (81.5) & $185(75.8)$ & \\
\hline $\mathrm{CABG}$ & $543(7.4)$ & $21(8.6)$ & \\
\hline Medical & 811 (11.1) & 38 (15.6) & \\
\hline
\end{tabular}

Continuous variables presented as mean (\%).

$\mathrm{AF}$, atrial fibrillation; $\mathrm{BMI}$, body mass index; $\mathrm{CABG}$, coronary artery bypass graft; COPD, chronic obstructive pulmonary disease; CV, cardiovascular; ED, emergency department; GP, general practitioner; MI, myocardial infarction; NSTEMI, non-ST elevation myocardial infarction; $\mathrm{PCl}$, percutaneous coronary intervention; SBP, systolic blood pressure; STEMI, ST elevation myocardial infarction.

with a history of AF also had significantly lower EQ-5D UK-weighted index scores than those without AF. Results from a multivariable logistic regression identified five QoL measures that were associated with history of AF after adjustment (figure 2). These included the EQ-5D UK-weighted index score, the EQ-5D visual analogue scale score and two individual domains from the EQ-5D assessment (usual activities, pain/discomfort).

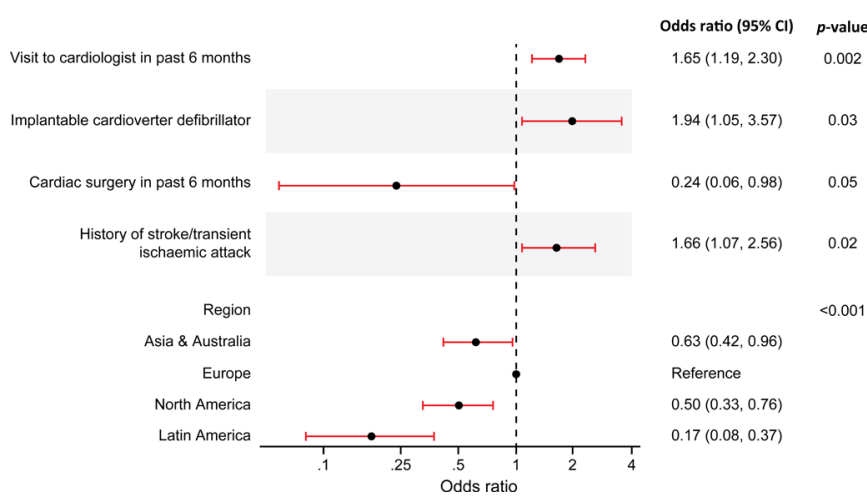

Figure 1 Baseline factors independently associated with oral anticoagulant use at enrolment in patients with a history of atrial fibrillation $(n=702)$. 
Table 3 EQ-5D quality of life assessment by history of atrial fibrillation at enrolment

\begin{tabular}{|c|c|c|c|}
\hline Variable & $\begin{array}{l}\text { No history of AF } \\
(\mathrm{N}=7534)\end{array}$ & $\begin{array}{l}\text { History of AF } \\
(\mathrm{N}=700)\end{array}$ & $P$ value \\
\hline & \multicolumn{3}{|c|}{ Demographics \& clinical variables } \\
\hline \multicolumn{3}{|c|}{ EQ-5D UK-weighted index score } & $<0.0001$ \\
\hline 1 & 3559 (47.2) & $241(34.4)$ & \\
\hline $0.75-0.99$ & $1996(26.5)$ & $201(28.7)$ & \\
\hline $0.60-0.74$ & $1394(18.5)$ & 167 (23.9) & \\
\hline$<0.60$ & $585(7.8)$ & $91(13.0)$ & \\
\hline \multicolumn{3}{|l|}{ EQ-5D overall score } & $<0.0001$ \\
\hline 0 & 3559 (47.2) & $241(34.4)$ & \\
\hline 1 & $1670(22.2)$ & $146(20.9)$ & \\
\hline 2 & $1018(13.5)$ & $129(18.4)$ & \\
\hline 3 & $595(7.9)$ & $84(12.0)$ & \\
\hline$\geq 4$ & $692(9.2)$ & $100(14.3)$ & \\
\hline \multicolumn{3}{|l|}{ EQ-5D mobility } & $<0.0001$ \\
\hline No problems & $5656(75.1)$ & $438(62.6)$ & \\
\hline Some problems & $1868(24.8)$ & $260(37.1)$ & \\
\hline Severe problems & $12(0.2)$ & $2(0.3)$ & \\
\hline \multicolumn{3}{|l|}{$E Q-5 D$ self-care } & $<0.0001$ \\
\hline No problems & 7107 (94.3) & $627(89.6)$ & \\
\hline Some problems & $397(5.3)$ & $66(9.4)$ & \\
\hline Severe problems & $32(0.4)$ & $7(1.0)$ & \\
\hline \multicolumn{3}{|l|}{ EQ-5D usual activities } & $<0.0001$ \\
\hline No problems & $6161(81.8)$ & $482(68.9)$ & \\
\hline Some problems & $1292(17.1)$ & $200(28.6)$ & \\
\hline Severe problems & $82(1.1)$ & $18(2.6)$ & \\
\hline \multicolumn{3}{|l|}{ EQ-5D pain } & $<0.0001$ \\
\hline No problems & $4788(63.5)$ & $352(50.3)$ & \\
\hline Some problems & $2541(33.7)$ & $314(44.9)$ & \\
\hline Severe problems & $207(2.7)$ & $34(4.9)$ & \\
\hline \multicolumn{3}{|c|}{ EQ-5D depression/anxiety } & 0.31 \\
\hline No problems & $5713(75.8)$ & $544(77.7)$ & \\
\hline Some problems & $1679(22.3)$ & $143(20.4)$ & \\
\hline Severe problems & $143(1.9)$ & $13(1.9)$ & \\
\hline \multicolumn{3}{|c|}{ EQ-5D visual analogue scale score $(0-100)$} & $<0.0001$ \\
\hline $90-100$ & $2124(28.3)$ & $132(19.0)$ & \\
\hline $80-89$ & $2130(28.3)$ & $175(25.1)$ & \\
\hline $70-79$ & $1602(21.3)$ & $165(23.7)$ & \\
\hline $60-69$ & $740(9.8)$ & $101(14.5)$ & \\
\hline$<60$ & $921(12.3)$ & $123(17.7)$ & \\
\hline
\end{tabular}

Continuous variables presented as mean (\%). $n=49$ patients with missing baseline EQ-5D data.

$A F$, atrial fibrillation; EQ-5D, EuroQoL five dimensions questionnaire.

Patients with incident AF after enrolment ( $\mathrm{n}=245)$ reported worse QoL at enrolment among all domains except self-care $(p=0.12)$ and were similarly found to have significantly lower EQ-5D UK-weighted index scores than patients without incident AF (online supplemental table S5).

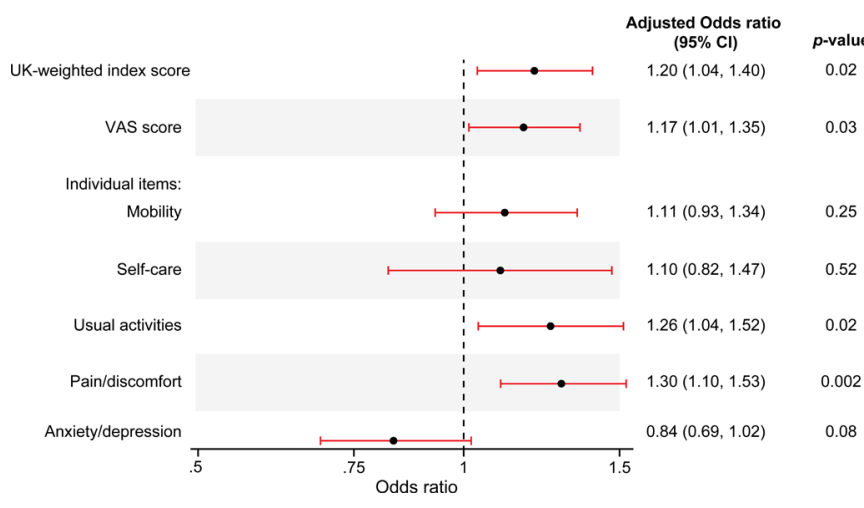

Figure 2 Adjusted associations between history of atrial fibrillation and self-reported QoL at baseline. QoL, quality of life; VAS, visual analogue scale. Estimated using ordinal logistic regression models for index score, VAS score and each individual domain. $\mathrm{OR}>1$ means that patients with a history of atrial fibrillation (AF) have poorer self-rated health than those with no history of AF. For instance, the adjusted common OR for VAS score is 1.17, which means that patients with a history of AF have $17 \%$ increased odds of being below any cut-off value $(<90,<80,<70$ or $<60)$ for the EQ-5D VAS score compared with patients with no history of AF. Adjusted for factors associated with baseline EQ-5D index score (sex, age, body mass index, heart rate, smoking status, years of education, diabetes, history of stroke, angina, peripheral vascular disease, peptic ulcer disease, chronic obstructive pulmonary disease, heart failure, anaemia, emergency department visit within the preceding 6 months, type of index myocardial infarction, diuretic use and geographical region).

\section{Predictors of incident atrial fibrillation}

Results from a multivariable logistic regression model identified four independent factors associated with development of incident AF (figure 3), including geographical region (highest odds of incident $\mathrm{AF}$ in European patients), history of angina, worse EQ-5D UK-weighted index score and ED visit for CV event or bleeding within 6 months before enrolment.

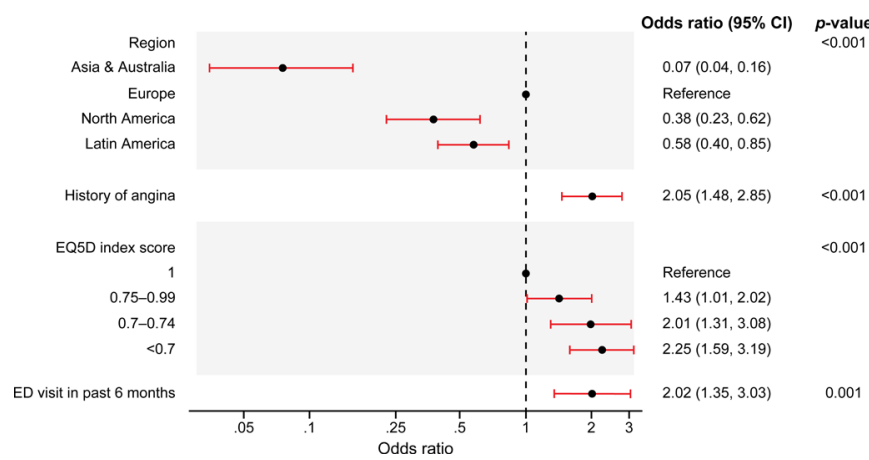

Figure 3 In patients without history of atrial fibrillation at enrolment $(n=7575)$, baseline factors independently associated with development of incident atrial fibrillation after registry enrolment. ED, emergency department; EQ-5D, EuroQoL five dimensions questionnaire. 
A

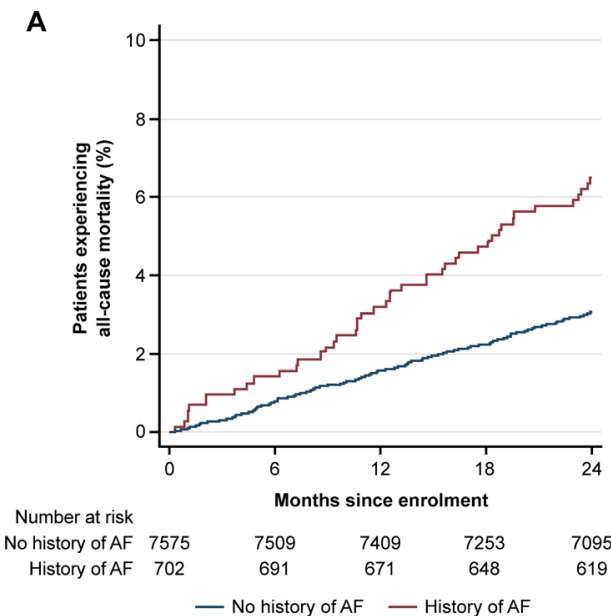

C

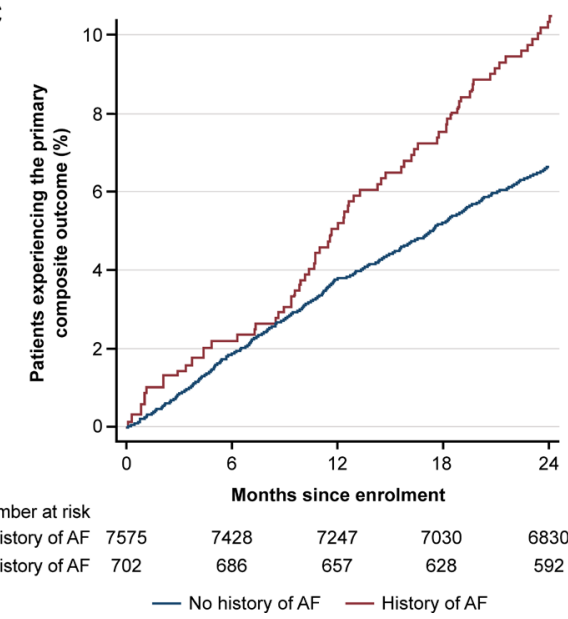

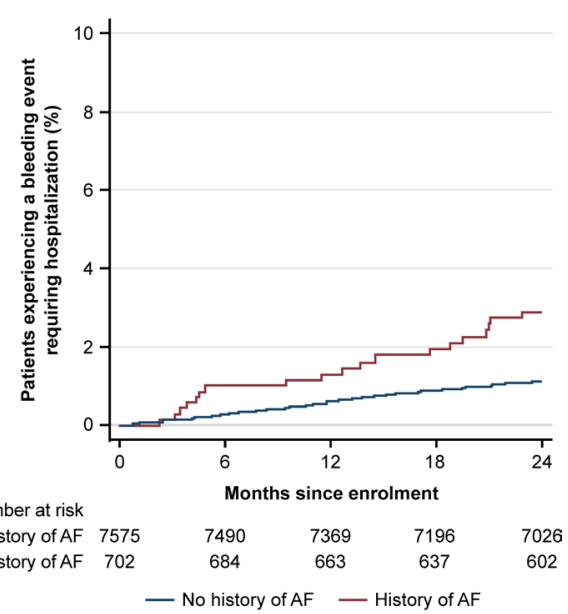

D

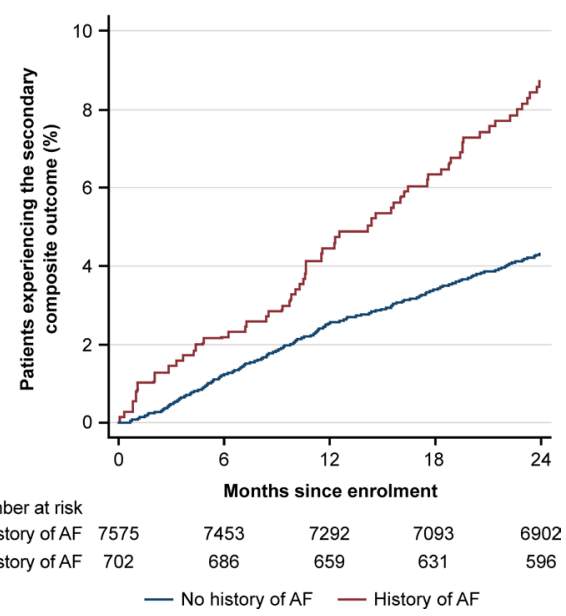

Figure 4 Cumulative incidence of (A) all-cause mortality, (B) bleeding requiring hospitalisation, (C) primary composite outcome and $(D)$ secondary composite outcome in patients with a history of atrial fibrillation at enrolment. Primary composite outcome: all-cause mortality, MI, stroke, unstable angina requiring urgent revascularisation. Secondary composite outcome: cardiovascular mortality, MI, stroke AF, atrial fibrillation. MI, myocardial infarction.

\section{Clinical outcomes and hospitalisations}

Compared with patients without AF, patients with a history of AF had a higher cumulative incidence of allcause mortality, stroke, bleeding requiring hospitalisation and primary and secondary composite outcomes over 2 years (supplemental table S6, figure 4). Unadjusted rate ratios of the composite outcomes, all-cause hospitalisation, all-cause mortality and bleeding requiring hospitalisation were higher among patients with a history of $\mathrm{AF}$ than those without AF (table 1). After multivariable adjustment, patients with a history of AF were found to have significantly higher rates of all-cause hospitalisation, but not the composite outcomes or all-cause mortality.

A total of 7179 patients had hospitalisation data available from every follow-up visit through 2 years. Patients with a history of AF before enrolment were more likely to experience all-cause hospitalisation (226/559 [40.4\%] vs 1693/6611 [25.6\%]; $\mathrm{p}<0.001$ ), cardiovascular hospitalisation $(83 / 559$ [14.9\%] vs 626/6611 [9.5\%]; $\mathrm{p}<0.001)$ and bleeding hospitalisation $(11 / 559$ [2.0\%] vs $61 / 6611$ [0.9\%]; $p=0.02$ ) over 2 years compared with patients without AF (figure 5). The mean length of stay for all-cause hospitalisation was longer for patients with a history of AF than for patients without AF (12.2 days [95\% CI 9.9 to 14.6 ] vs 9.6 days [95\% CI 8.9 to 10.3]; $\mathrm{p}=0.03$ ). There was no significant difference in length of hospital stay between groups for bleeding hospitalisation $(\mathrm{p}=0.50)$. After multivariable adjustment, patients with a history of AF were found to have significantly higher rates of all-cause hospitalisation than those without $\mathrm{AF}$ (table 1).

\section{DISCUSSION}

In our analysis of patients 1 to 3 years after MI, approximately $8 \%$ had a history of AF before enrolment and another $3 \%$ developed incident AF over 2 years of follow-up. Patients with AF (prior or incident) had a higher burden of comorbidities and worse QoL than patients without AF. Less than half of the patients with a history of AF were treated with $\mathrm{OAC}$ at the time of registry enrolment, and of those on $\mathrm{OAC}$, half were also on antiplatelet therapy, which is contrary to the most recent international guidelines that recommend 


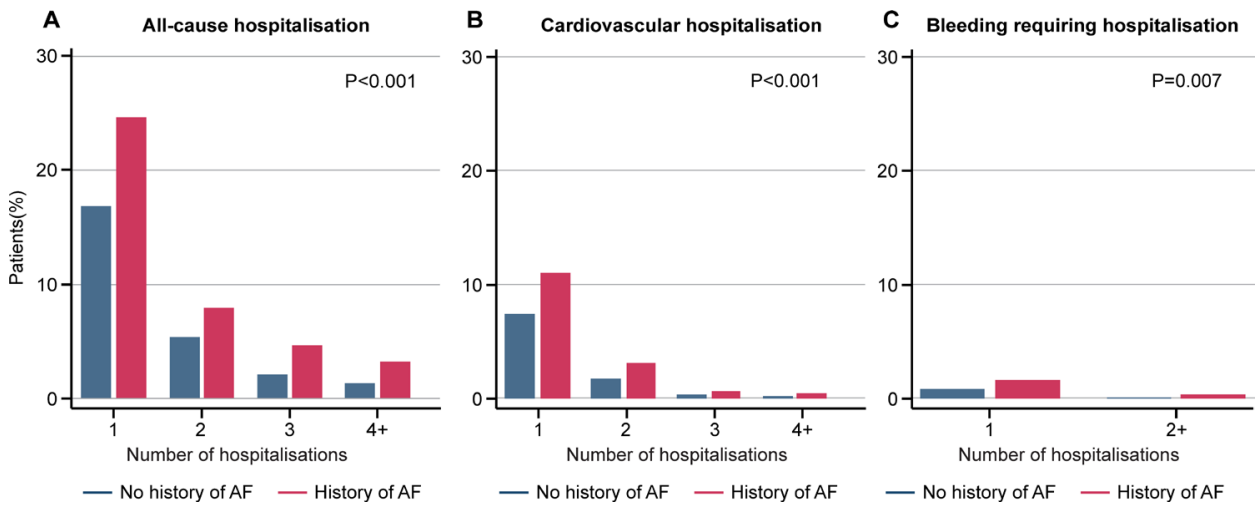

Figure 5 Occurrence of $(A)$ all-cause hospitalisation $(p<0.001)$, (B) cardiovascular hospitalisation $(p<0.001)$ and $(C)$ bleeding requiring hospitalisation ( $p=0.007$ ) during follow-up by history of atrial fibrillation at enrolment. The $p$ value was calculated to compare patients with no history of AF and patients with a history of AF. AF, atrial fibrillation.

discontinuation of antiplatelet therapy after 1 year. ${ }^{17} 18$ Patients with AF had a higher adjusted rate of all-cause hospitalisation and over 2 years than those without AF, but similar rates of mortality.

In this analysis, we demonstrate that $\mathrm{AF}$ is prevalent in patients with prior MI, with $8.5 \%$ of patients from the TIGRIS registry having a history of AF at enrolment. This is consistent with prior observational studies. ${ }^{1-3}$ Because $\mathrm{AF}$ is a known risk factor for $\mathrm{MI},{ }^{19}$ the importance of close monitoring and aggressive treatment of other modifiable risk factors is of paramount importance in this population. A significant number of patients in our analysis developed incident $\mathrm{AF}$ over the 2-year follow-up period (incidence rate 16.5 [95\% CI 14.6 to 18.8] per 1000 person-years). Data from the prospective Rotterdam study reveal similar incidence rates of $\mathrm{AF}$, ranging from 1.1 per 1000 person-years in the younger group (age 55-59 years) to 20.7 per 1000 person-years in the older group (age 80-84). ${ }^{20}$ Given the significant rates of incident $\mathrm{AF}$ in patients after MI, clinicians should maintain heightened awareness for signs and symptoms of AF in this population. Despite the high risk, the role of routine surveillance is undefined.

Our data show that patients with comorbid AF and prior $\mathrm{MI}$ are at high risk for thromboembolism and bleeding. The vast majority $(97.7 \%)$ of patients with a history of $\mathrm{AF}$ in our analysis had a $\mathrm{CHA}_{2} \mathrm{DS}_{2}$-VASc score $\geq 2$ (corresponding to a $\geq 2.2 \%$ per year risk of thromboembolism in untreated patients) and over $20 \%$ had a $\mathrm{CHA}_{2} \mathrm{DS}_{2}-$ VASc score $\geq 6$ (corresponding to a $\geq 9.8 \%$ per year risk of thromboembolism in untreated patients). ${ }^{5}$ Although the unadjusted rates of all-cause mortality, cardiovascular mortality and bleeding requiring hospitalisation were higher in patients with AF, only a difference for all-cause hospitalisation persisted after multivariable adjustment. Notably, approximately $50 \%$ of patients with $\mathrm{AF}$ in this analysis who were on OAC were also on concomitant antiplatelet therapy, which likely influenced bleeding events during follow-up.

Despite the high thromboembolic risk in patients with prior MI and concomitant AF, remarkably, less than half
(49.6\%) of the patients with a history of AF were on OAC at enrolment. Furthermore, after 2 years of follow-up, a net increase in OAC was found in only 12 patients. These data demonstrate little change in practice patterns compared with prior reports that show vast underuse of $\mathrm{OAC}$ in patients with $\mathrm{AF}$, both with warfarin ${ }^{21}$ and with direct OAC. ${ }^{22}$ The underuse of OAC in patients with AF represents an enormous opportunity to improve patient outcomes because OAC reduces the risk of stroke in patients with AF by more than $60 \% .{ }^{23}$ In addition, international guidelines on concomitant use of OAC and antiplatelet agents were updated after our study period, now recommending discontinuation of antiplatelet therapy altogether in 1-year post-MI stable patients on OAC. ${ }^{17}$ Changes in international practice patterns after the release of updated guidelines are not well described; however, our data suggest that a significant opportunity likely exists to discontinue antiplatelet therapy in eligible patients.

An important and unique feature of our analysis is in the assessment of QoL among registry participants. Our analysis showed that patients with a history of AF or incident AF have poorer QoL scores at enrolment than those without AF. Several QoL domains were independently associated with history of AF, and the EQ-5D UK-weighted index score was further found to be independently associated with development of incident AF. Patient-reported outcomes such as QoL have been increasingly recognised as important measures of quality of care. ${ }^{24}$ Prior studies have further suggested that QoL measures may predict hospitalisation and mortality in patients with $\mathrm{AF}^{25}$ The association between atrial fibrillation and poorer qualityof-life measures warrants further investigation to better understand the factors driving this linkage. Clinicians should consider the potential impact that atrial fibrillation may have on patient-centred outcomes such as quality of life.

Our analysis carries several limitations, including those inherent to all observational registries. Although the TIGRIS registry includes representation from 24 countries, this population may not be widely generalisable. 
Warfarin was used in $>50 \%$ of patients with AF on OAC in this study. Given the increase in alternative OAC prescription since our study period, clinical outcomes may differ in a more contemporary cohort. Despite our use of robust multivariable models, the possibility of unmeasured confounding exists, which limits the interpretation of associations identified. The TIGRIS registry lacks detailed data describing reasons for deferral of OAC, which would be helpful in identifying interventions to overcome this gap in care. Lastly, the diagnosis of AF based on clinical observation rather than specialised device monitoring may have led to underdiagnosis in the study population.

In conclusion, $\mathrm{AF}$ is common in patients with prior MI and is associated with poorer QoL and increased risk of clinical outcomes than those without AF. Despite the increased risk of clinical outcomes, OAC remains underused, whereas antiplatelet therapy with OAC is overused. Effective strategies are needed to increase the use of OAC and thus improve clinical outcomes.

\section{Author affiliations}

${ }^{1}$ Duke University Hospital, Durham, North Carolina, USA

'London School of Hygiene \& Tropical Medicine, London, UK

${ }^{3}$ Medical Statistics, London School of Hygiene \& Tropical Medicine, London, UK

${ }^{4}$ Cardiology, Concord Hospital and University of Sydney, Sydney, New South Wales,

\section{Australia}

${ }^{5}$ Department of Cardiovascular Medicine, Tohoku University Graduate School of Medicine, Sendai, Japan

${ }^{6}$ Instituto do Coracao (InCor), Hospital das Clínicas HCFMUSP, Faculdade de Medicina, Universidade de Sao Paulo Instituto do Coracao, Sao Paulo, Brazil

${ }^{7}$ Terrence Donnelly Heart Centre, St Michael's Hospital, University of Toronto Faculty of Medicine, Toronto, Ontario, Canada

${ }^{8}$ Cardiovascular Division Medicine, University of Miami Miller School of Medicine, Miami, Florida, USA

${ }^{9}$ Department of Clinical Pharmacology and Clinical Research Platform of East of Paris, Assistance Publique - Hopitaux de Paris, Paris, France

${ }^{10} \mathrm{Clinical}$ Pharmacology—Research Platform (UPMC-Paris 06), Sorbonne Université, Paris, France

${ }^{11}$ Department of General and Interventional Cardiology, University Heart Center, University Medical Center Hamburg-Eppendorf, Hamburg, Germany

${ }^{12}$ Partner Site Hamburg/Lübeck/Kiel, German Center for Cardiovascular Research (DZHK), Hamburg, Germany

${ }^{13}$ AstraZeneca R\&D Gothenburg, Goteborg, Sweden

${ }^{14}$ Duke Clinical Research Institute, Duke University Medical Center, Durham, North Carolina, USA

Acknowledgements The authors thank Gunnar Brandrup-Wognsen for his contributions to this manuscript.

Contributors APC, CBG, R0 and SJP contributed to the conception and design, data analysis and interpretation of data and drafting and writing the final version of the manuscript. DBB, SY, JCN, SGG, MGC, TS, DW, KH and KAS participated in the conduct of the registry and revision of the manuscript. CBG is the guarantor and accepts full responsibility for the work and/or the conduct of the study, had access to the data and controlled the decision to publish.

Funding The manuscript draft was written by the first author, and all coauthors provided inputs and comments. Data analyses were conducted by R0 and S.PP (London School of Hygiene and Tropical Medicine, London, UK). Editorial support was provided by Cactus Communications and funded by AstraZeneca. The long Term rlsk, clinical manaGement and healthcare Resource utilization of stable coronary artery dISease (TIGRIS) registry is sponsored by AstraZeneca AB, Södertälje, Sweden. The sponsor contributed to the registry conception and design, and commented on the analyses.
Competing interests APC reports grant funding from the National Institutes of Health. RO has received research grant support from AstraZeneca. SJP has received research grant support from AstraZeneca. DBB has received speaker/ consulting honoraria and/or research grant support from Amgen, AstraZeneca, Bayer, Boehringer Ingelheim, BMS, Eli Lilly, Merck and Sanofi. SY has received speaker/consulting honoraria and/or research grant support from Takeda, Daiichi Sankyo, AstraZeneca, Boehringer Ingelheim and BMS. JCN has received speaker/ consulting honoraria and/or research grant support from Amgen, AstraZeneca, Bayer, BMS, Boehringer Ingelheim, GSK, Merck, Novartis, Pfizer and Sanofi. SGG has received research grant support (eg, steering committee or data and safety monitoring committee) and/or speaker/consulting honoraria (eg, advisory boards) from Amgen, AstraZeneca, Bayer, Boehringer Ingelheim, Bristol Myers Squibb, CSL Behring, Daiichi Sankyo/American Regent, Eli Lilly, Esperion, Ferring Pharmaceuticals, GlaxoSmithKline, HLS Therapeutics, Janssen/Johnson \& Johnson, Merck, Novartis, Novo Nordisk A/C, Pendopharm, Pfizer, Regeneron, Sanofi, Servier and Valeo Pharma, and salary support/honoraria from the Heart and Stroke Foundation of Ontario/University of Toronto (Polo) Chair, Canadian Heart Research Centre and MD Primer, Canadian VIGOUR Centre, Cleveland Clinic Coordinating Center for Clinical Research, Duke Clinical Research Institute, New York University Clinical Coordinating Center and PERFUSE Research Institute. MGC has received speaker/consulting honoraria and/or research grant support from AstraZeneca, Medtronic, Abiomed and Merit Medical. TS has received speaker/consulting honoraria and/or research grant support from Astellas, Amgen, AstraZeneca, Bayer, Boehringer Ingelheim, Eli Lilly, GlaxoSmithKline, Merck, Novartis, Pfizer and Sanofi. DW has received speaker/consulting honoraria and/or research grant support from AstraZeneca, Bayer, Berlin-Chemie, Biotronik and Novartis. KH and KAS are employees of AstraZeneca. CBG has received consulting honoraria and/or research grant support from Armetheon, AstraZeneca, Bayer, Boehringer Ingelheim, BMS, Daiichi Sankyo, Eli Lilly, Gilead, GlaxoSmithKline, Hoffmann-La Roche, Janssen, Medtronic, Pfizer, Salix Pharmaceuticals, Sanofi, Takeda and The Medicines Company.

Patient consent for publication Not applicable.

Ethics approval All patients provided written informed consent. This study involves human participants and was approved by the corresponding health authorities and ethics boards for all participating study sites. This includes China HGR approval of inclusion of 750 Chinese patients. Participants gave informed consent to participate in the study before taking part.

Provenance and peer review Not commissioned; externally peer reviewed.

Data availability statement All data relevant to the study are included in the article or uploaded as online supplemental information. Baseline patient characteristics and data on long-term oral antiplatelet use and event rates in the TIGRIS registry have been published elsewhere (all open access).

Open access This is an open access article distributed in accordance with the Creative Commons Attribution Non Commercial (CC BY-NC 4.0) license, which permits others to distribute, remix, adapt, build upon this work non-commercially, and license their derivative works on different terms, provided the original work is properly cited, appropriate credit is given, any changes made indicated, and the use is non-commercial. See: http://creativecommons.org/licenses/by-nc/4.0/.

ORCID iDs

Anthony P Carnicelli http://orcid.org/0000-0002-9805-4562

Stuart J Pocock http://orcid.org/0000-0003-2212-4007

David B Brieger http://orcid.org/0000-0001-6115-0326

Dirk Westermann http://orcid.org/0000-0002-7542-1956

Christopher B Granger http://orcid.org/0000-0002-0045-3291

\section{REFERENCES}

1 Saczynski JS, McManus D, Zhou Z, et al. Trends in atrial fibrillation complicating acute myocardial infarction. Am J Cardiol 2009;104:169-74.

2 Lopes RD, Li L, Granger CB, et al. Atrial fibrillation and acute myocardial infarction: antithrombotic therapy and outcomes. Am J Med 2012;125:897-905.

3 Zeymer U, Annemans L, Danchin N, et al. Impact of known or newonset atrial fibrillation on 2-year cardiovascular event rate in patients with acute coronary syndromes: results from the prospective EPICOR Registry. Eur Heart J Acute Cardiovasc Care 2019;8:121-9.

4 Lin HJ, Wolf PA, Benjamin EJ, et al. Newly diagnosed atrial fibrillation and acute stroke. The Framingham Study. Stroke 1995;26:1527-30.

5 Hindricks G, Potpara T, Dagres N, et al. 2020 ESC guidelines for the diagnosis and management of atrial fibrillation developed in 
collaboration with the European Association for Cardio-Thoracic Surgery (EACTS). Eur Heart J 2021;42:373-498.

6 Sørensen R, Hansen ML, Abildstrom SZ, et al. Risk of bleeding in patients with acute myocardial infarction treated with different combinations of aspirin, clopidogrel, and vitamin $\mathrm{K}$ antagonists in Denmark: a retrospective analysis of nationwide registry data. Lancet 2009;374:1967-74.

7 Jabre $\mathrm{P}$, Jouven X, Adnet F, et al. Atrial fibrillation and death after myocardial infarction: a community study. Circulation 2011;123:2094-100.

8 Westermann D, Goodman SG, Nicolau JC, et al. Rationale and design of the long-Term rlsk, clinical manaGement, and healthcare Resource utilization of stable coronary artery dISease in post-myocardial infarction patients (TIGRIS) study. Clin Cardiol 2017:40:1197-204.

9 Goodman SG, Nicolau JC, Requena G, et al. Longer-term oral antiplatelet use in stable post-myocardial infarction patients: insights from the long Term rlsk, clinical manaGement and healthcare Resource utilization of stable coronary artery dlSease (TIGRIS) observational study. Int J Cardiol 2017;236:54-60.

10 Brooks R. EuroQol: the current state of play. Health Policy 1996;37:53-72.

11 Ellis JJ, Eagle KA, Kline-Rogers EM, et al. Validation of the EQ-5D in patients with a history of acute coronary syndrome. Curr Med Res Opin 2005;21:1209-16.

12 Nowels D, McGloin J, Westfall JM, et al. Validation of the EQ-5D quality of life instrument in patients after myocardial infarction. Qual Life Res 2005;14:95-105.

13 Berg J, Lindgren P, Nieuwlaat R, et al. Factors determining utility measured with the EQ-5D in patients with atrial fibrillation. Qual Life Res 2010;19:381-90.

14 Spertus J, Dorian P, Bubien R, et al. Development and validation of the Atrial Fibrillation Effect on QualiTy-of-Life (AFEQT) Questionnaire in patients with atrial fibrillation. Circ Arrhythm Electrophysiol 2011;4:15-25.
15 Dolan P. Modeling valuations for EuroQol health states. Med Care 1997;35:1095-108.

16 Pocock SJ, Brieger D, Gregson J, et al. Predicting risk of cardiovascular events 1 to 3 years post-myocardial infarction using a global registry. Clin Cardiol 2020;43:24-32.

17 Collet J-P, Thiele H, Barbato E, et al. 2020 ESC Guidelines for the management of acute coronary syndromes in patients presenting without persistent ST-segment elevation. Eur Heart $J$ 2021;42:1289-367.

18 Andrade JG, Aguilar M, Atzema C, et al. The 2020 Canadian Cardiovascular Society/Canadian Heart Rhythm Society comprehensive guidelines for the management of atrial fibrillation. Can J Cardiol 2020;36:1847-948.

19 Soliman EZ, Safford MM, Muntner P, et al. Atrial fibrillation and the risk of myocardial infarction. JAMA Intern Med 2014;174:107-14.

20 Heeringa J, van der Kuip DAM, Hofman A, et al. Prevalence, incidence and lifetime risk of atrial fibrillation: the Rotterdam study. Eur Heart J 2006;27:949-53.

21 Ogilvie IM, Newton N, Welner SA, et al. Underuse of oral anticoagulants in atrial fibrillation: a systematic review. Am J Med 2010;123:638-45.

22 Rose AJ, Goldberg R, McManus DD, et al. Anticoagulant prescribing for non-valvular atrial fibrillation in the veterans health administration. J Am Heart Assoc 2019;8:e012646.

23 Risk factors for stroke and efficacy of antithrombotic therapy in atrial fibrillation. Analysis of pooled data from five randomized controlled trials. Arch Intern Med 1994;154:1449-57.

24 Weldring T, Smith SMS. Patient-reported outcomes (PROs) and patient-reported outcome measures (PROMs). Health Serv Insights 2013;6:61-8.

25 Schron E, Friedmann E, Thomas SA. Does health-related quality of life predict hospitalization or mortality in patients with atrial fibrillation? J Cardiovasc Electrophysiol 2014;25:23-8. 